\title{
Femoral nerve block for analgesia in fractures of the femoral neck
}

\author{
B. J. FINLAYSON \& T. J. UNDERHILL \\ Accident and Emergency Department, University Hospital, Nottingham, England
}

\section{SUMMARY}

The purpose of this study was to investigate the efficacy of femoral nerve blocks in patients with fractures of the neck of the femur. Thirty-six patients with femoral neck fractures attending the accident department over a three month period received femoral blocks from one of the two authors. The effect of the block was assessed both subjectively and objectively. Thirty patients reported a worthwhile reduction in pain following the procedure and this was supported by objective blockade in 29. In all six patients who reported no benefit, the block failed objectively. There were no complications of the procedure.

\section{INTRODUCTION}

Fracture of the femoral neck is most commonly an affliction of the elderly. These elderly people are often in severe pain exacerbated by any movement, and the application of satisfactory splintage or traction is usually impracticable in the A\&E department. Clinicians are frequently reluctant to administer adequate parenteral analgesia to these patients, for fear of worsening intercurrent disease or of precipitating unwanted sideeffects in patients who are often already frail. Local anaesthetic blockade of the femoral nerve at the level of the inguinal ligament is a well-described and efficient technique in achieving analgesia in fractures of the femoral shaft (McGlone et al., 1987; Tondare \& Nadkarni, 1982; Grossbard \& Love, 1979), and has been used together with light sedation for femoral neck surgery (Howard et al., 1983).

The purpose of this study was to investigate the efficacy of such nerve blocks in fractures of the femoral neck.

Correspondence: Mr B. F. Finlayson, Accident and Emergency Department, Norfolk and Norwich Hospital, Brunswick Road, Norwich, England 


\section{METHOD}

Femoral nerve blocks were performed using the following technique (Khoo \& Browni

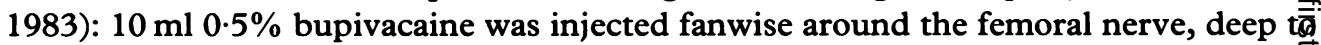
the fascia iliaca, lateral and deep to the femoral artery, $1 \mathrm{~cm}$ distal to the inguin ligament, taking care to avoid intra-arterial injection. The block was assessed in tw. ways, objectively by testing pin-prick and light touch sensation in the femoral nerve territory and subjectively by asking the patient whether their pain was worse्్ unchanged, reduced or absent. The fractures were classified as intracapsular of extracapsular. Injection of local anaesthetic into the joint (i.e. haematoma block) wå excluded by repeated aspiration during the procedure.

\section{PATIENTS}

Blocks were performed on patients in the A\&E department with radiologically proven fractures, over a three month period. Those patients with whom communication was difficult were excluded from the study. These included patients with dementia, \& severe communication difficulties e.g. strokes and those patients with a poor unde $\overrightarrow{\mathbb{P}_{3}}$ standing of English. Also excluded were those patients with groin infections or gro obesity.

\section{RESULTS}

Thirty-six blocks were performed on 36 patients, 29 female and 7 male. The age rang was 31 to 95 years with a mean age of 78 (s.d. 13). Two of the men were young, 31 an $\vec{f}$ 44, one of whom had multiple injuries. Pain was completely abolished in 4 patient reduced in 26 and remained the same in 6 . No one reported worsening of their paig. (Table 1).

Objective blockade was achieved in all but 7 patients, the 6 who reported no benefit and one who reported reduced pain. The 4 patients in whom the pain was abolished hal extracapsular fractures and those with reduced pain were evenly distributed between the two groups (Table 2). Intracapsular injection was avoided in all cases.

The case notes of all the patients were examined after discharge from the ward, of death, to determine whether there had been any complications related to the blocks; there were none.

\section{DISCUSSION}

The innervation of the periosteum of the femoral neck is unclear but Hilton's law state्क्षs that the sensory supply to a joint is derived from the nerves to the muscles acting across 
Table 1 Results

\begin{tabular}{|c|c|c|c|c|}
\hline \multirow[b]{2}{*}{ Patient no. } & \multirow[b]{2}{*}{ Fracture } & \multirow[b]{2}{*}{ Age } & \multicolumn{2}{|c|}{ Assessment } \\
\hline & & & Objective & Subjective \\
\hline 1 & extracapsular & 75 & reduced & reduced \\
\hline 2 & intracapsular & 80 & reduced & reduced \\
\hline 3 & intracapsular & 76 & reduced & reduced \\
\hline 4 & extracapsular & 81 & no change & reduced \\
\hline 5 & extracapsular & 31 & reduced & absent \\
\hline 6 & extracapsular & 78 & reduced & reduced \\
\hline 7 & intracapsular & 73 & no change & no change \\
\hline 8 & intracapsular & 84 & reduced & reduced \\
\hline 9 & intracapsular & 77 & reduced & reduced \\
\hline 10 & intracapsular & 85 & no change & no change \\
\hline 11 & extracapsular & 86 & reduced & reduced \\
\hline 12 & extracapsular & 78 & reduced & absent \\
\hline 13 & extracapsular & 87 & reduced & reduced \\
\hline 14 & intracapsular & 86 & no change & no change \\
\hline 15 & extracapsular & 91 & reduced & reduced \\
\hline 16 & extracapsular & 87 & reduced & reduced \\
\hline 17 & intracapsular & 74 & reduced & reduced \\
\hline 18 & intracapsular & 80 & no change & no change \\
\hline 19 & intracapsular & 92 & reduced & reduced \\
\hline 20 & extracapsular & 88 & reduced & reduced \\
\hline 21 & intracapsular & 69 & reduced & reduced \\
\hline 22 & intracapsular & 79 & reduced & reduced \\
\hline 23 & extracapsular & 95 & reduced & reduced \\
\hline 24 & extracapsular & 79 & reduced & reduced \\
\hline 25 & intracapsular & 95 & reduced & reduced \\
\hline 26 & extracapsular & 83 & reduced & reduced \\
\hline 27 & intracapsular & 68 & reduced & reduced \\
\hline 28 & intracapsular & 81 & reduced & reduced \\
\hline 29 & intracapsular & 72 & reduced & reduced \\
\hline 30 & extracapsular & 44 & reduced & absent \\
\hline 31 & intracapsular & 80 & no change & no change \\
\hline 32 & intracapsular & 84 & reduced & reduced \\
\hline 33 & intracapsular & 73 & reduced & reduced \\
\hline 34 & extracapsular & 63 & reduced & reduced \\
\hline 35 & intracapsular & 77 & no change & no change \\
\hline 36 & extracapsular & 62 & reduced & absent \\
\hline \multicolumn{3}{|c|}{ Total extracapsular: 16} & \multicolumn{2}{|c|}{ Total intracapsular: 20} \\
\hline
\end{tabular}

Table 2 Subjective pain level

\begin{tabular}{lccc}
\hline & No change & Reduced & Absent \\
\hline Intracapsular & 6 & 14 & 0 \\
Extracapsular & 0 & 12 & 4 \\
\hline
\end{tabular}


the joint. This is probably more relevant when considering proprioceptive tha periosteal nociceptive innervation, but it may be assumed that pain from femoral nec⿱乛⿰冫⿰亅⿱丿丶丶 fractures is conducted in the femoral, the obturator and the sciatic nerves, to a greater of

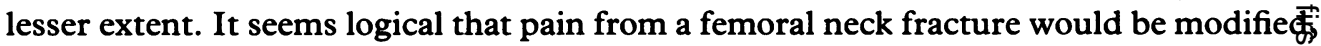
but not abolished, by femoral nerve blockade, and this is reflected in the results of the study. The majority of patients who received blocks felt that worthwhile pain relief was achieved, and the absence of complications encountered implies that the technique safe. None of the patients who received effective blocks required further analgesia in the A\&E department, whereas all of those with failed blocks needed parenteral analgesia

It is interesting to note that the four patients in whom the pain was abolished had extracapsular fractures, whereas none of the patients with intracapsular fractures had complete pain relief. This may be because the more distal the fracture, the more likely is to have a dominant femoral nerve supply.

In conclusion, we feel that femoral nerve blockade is a simple, safe and effective method of achieving pain relief in patients with fractures of the femoral neck, and wouf recommend more widespread use of the technique.

\section{REFERENCES}

McGlone R., Sadrha K., Hamer D. W. \& Pritty P. E. (1987) Femoral nerve block in the initial management of femoral shaft fractures. Archives of Emergency Medicine 4, 163-68.

Tondare A.S. \& Nadkarni A.V. (1982) Femoral nerve block for fractured shaft of femur. Can Anaesthetists Society fournal 29, 270-71.

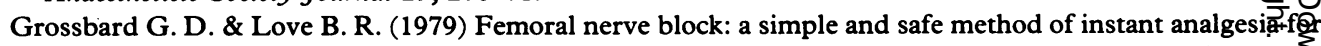
femoral shaft fractures in children. Australian and New Zealand fournal of Surgery 49, 592-94.

Howard C. B., Mackie I. G., Fairclough J. \& Austin T.R. (1983) Femoral neck surgery using a loç anaesthetic technique. Anaesthesia 38, 993-4.

Khoo S. T. \& Brown T. C. (1983) Femoral nerve block-the anatomical basis for a single injection technique Anaesthesia and Intensive Care 11, 40-2. 